\title{
THOSE WHO FAVOUR FIRE
}

\author{
A final farewell.
}

\section{BY CB DROEGE}

C arlos stares from the viewport of the control room in Construction Station Zeta, and watches the husk of sooty dirt that is Earth rotate beneath him. Soon, he will get a message, and he will push a button. He's sat in chairs like this one before, and pushed buttons like these after calls like the one he's expecting. This time, though, a part of him hopes the call won't come.

Carlos has a particular speciality, one that only a few others in the Solar System practise. When he pushes this button nearly a decade of planning, setting up, drilling and filling will culminate in a detonation that carefully disassembles the planet. The crust, mostly as particulates, will move out into a distant orbit around the main mass, and the mantle beneath will separate into about 150 similarly sized chunks, and drift away from the core, which will remain in its location relative to its orbit around Sol.

It'll take only about an hour for everything to break apart and then his job will be done, and the real work will begin. The ores of the planet, especially those in the now-rapidly cooling core, will become available for collection and processing. The iron, nickel and gold in the depths of the planet alone will help create enough new spincities for a thousand times the population that the surface of the planet was ever able to support, even before it was ruined.

Carlos watches a cyclone form in the swirling brownish-green clouds of Earth's atmosphere. So opaque are the clouds that he can't even tell where on the surface this storm is focused. He knows the surface well, of course; possibly better than anyone else in the system, not that that says much. He's had maps of the planet coursing through his office and his head for the past ten years, although he never actually visited the surface himself. No human has stepped foot on the world in two centuries. All the real work of this project was performed by drones controlled from orbit.

Carlos pushed the button for Ganymede

DNATURE.COM

Follow Futures:

๖ @NatureFutures

$f$ go.nature.com/mtoodm and Titan before this; he was watching from a distance when the button was pushed for Luna; he was on

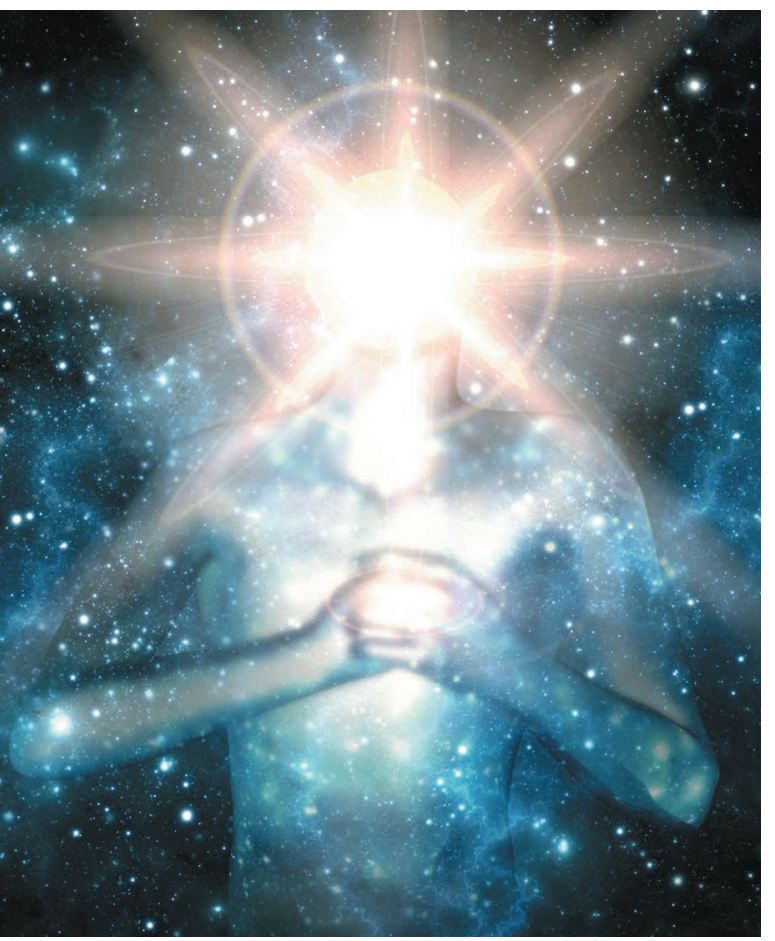

younger men and women could move on to other careers, but, especially for the few who have been in it as long as he has, or longer, this is it. The last one. There will be no need for celestial demolition projects once this one is complete. Not until humanity reaches a new stellar system somewhere, but Carlos will not be there that day.

Perhaps, at long last, the powers above will change their minds. The Consortium might decide that they don't need the material of Earth after all. For all the talk of building new homes for our expanding population, most spincities are only at about $80 \%$ capacity, and that's with the generous living space and resource requirements set up by the Sol Council. Really, each station can safely support $50 \%$ more population than they have laid out.

He knows that a last-second reprieve is not realistic, though. There is too much invested. Too many powerful people have too much at stake, and, in the end, no one really seems to care if Earth is taken apart. The Sol the team behind the dismantling of Titan, Pluto and Mercury; and consulted on a dozen others.

He's not sure what he expects to be different for this one. Protestors? Bottles of champagne? Crying babies?

He turns away from the viewport. The entire team is simply monitoring the progress solemnly. He supposes there was really no reason to think of this as a special occasion. Earth had birthed the human race, but had long-since outlived its usefulness as a habitat. There was celebration and mourning when the last humans departed the planet, but there was no reason for it now. It's only sentimentality that has kept the world from being harvested this long.

Every other solid body in the Solar System has been dismantled. Only Earth remains, and now its day has come. Humanity needs the raw materials more than it needs the sentiment.

Perhaps it is that Carlos's own usefulness is at an end that makes him see this project differently. A long career in the celestial mining industry, and this button today represents his retirement. He studies his team: 50 men and women of various disciplines, all working under his direction towards this goal. Pressing the button will also mean retirement for some of them. Some of the Council was unanimous on the issue - an astronomically rare event. Of the people in this room, as far as Carlos can tell, it is only he who is hesitant. At the very least, it should be an event of great importance, a thing that matters to people. As far as anyone knows, Earth is still the only place in the Universe where life came about, and it's about to be destroyed forever.

Ancient texts tell stories of the 'apocalypse', a terrible day of reckoning in which Earth is torn asunder, and now, by Carlos's hand, that day is here. He is the agent of that destruction. It's not coming on the backs of four skeletal horses, but on tight-beam radio waves, which will begin a detonation sequence to unleash approximately $3 \times 10^{25}$ joules from explosive material snaked throughout the planet.

A call comes in, and the young man who answers it flips a thumbs-up over to Carlos. Almost without thinking, he turns and pushes the button. He can't see anything yet, but he knows the end of the world has begun.

CB Droege is an author and voice actor from the Queen City living in the Millionendorf. His latest book is Peacemaker and Other Stories. He recently edited Starward Tales II: Another Anthology of Speculative Legends. 